\title{
Evaluation of fouling potential of nanofiltration membranes based on the dynamic contact angle measurements
}

\author{
Marek Gryta ${ }^{1}$, Justyna Bastrzyk ${ }^{1}$, Diana Lech ${ }^{2}$ \\ ${ }^{1}$ West Pomeranian University of Technology, Szczecin, Institute of Chemical Technology and Environment Engineering, \\ ul. Pułaskiego 10, 70-322 Szczecin, Poland, e-mail: Marek.Gryta@zut.edu.pl \\ ${ }^{2}$ Yale University (USA), The Department of Molecular, Cellular and Developmental Biology
}

\begin{abstract}
In this work the studies were performed on the intensity of fouling of the membrane NF90 and NF270 depending on the value of dynamic contact angle, previously determined for these membrane. The NF membranes were used for the separation of broth obtained during the fermentation of glycerol by Lactobacillus casei bacteria. The measurements of dynamic contact angle were carried out using the Wilhelmy plate method. Taped membranes samples (support layer to support layer), wetted for 2 days in deionized water prior to testing, were used to study the contact angle of top layer and its organic fouling. Using deionized water; the contact angle values equal to $27-30^{\circ}$ and $53-57^{\circ}$ for NF270 and NF90, respectively, were obtained. As a consequence of adsorption of organic compound on the membrane surfaces, the contact angle obtained for both fouled membranes was about $55-56^{\circ}$, and this value was closer to the contact angle of non-fouled NF90 membrane. Therefore, the NF90 membrane was more resistant to organic fouling during the separation of broth.
\end{abstract}

Keywords: nanofiltration, dynamic contact angle, fouling, Wilhelmy plate method, glycerol fermentation.

\section{INTRODUCTION}

Pressure driven membrane processes have found wide use in water purification and treatment technology. These processes can be applied for water desalination in order to obtain fresh water, as well as for wastewater treatment and deionized water (DI) production for industrial applications, e.g. power plant water supplying ${ }^{1-4}$. Nanofiltration (NF) is a promising technique for drinking water production from surface and ground water. However, membrane processes frequently experience significant fouling, which cause an undesirable permeate flux decline $e^{2-5}$.

The extent and type of fouling depends on the characteristics of separated solutions; therefore, proper feed characterization is important in the prediction of fouling propensity and the determination of how it can best be mitigated ${ }^{2-6}$. Water constituents such as particles, colloids, salts, natural organic matter (NOM), and soluble microbial products derived from biological wastewater treatment can adsorb and deposit onto membrane surfaces resulting in membrane fouling. Organic fouling is mainly associated with adsorption of dissolved or colloidal organic material on the membrane surface. This can be adsorption at a molecular level or the formation of a gel on the membrane surface ${ }^{3-7}$.

Traditional preventive strategies can be grouped under the operational solutions (e.g. pre-treatment to alter feed composition, use of high velocity and turbulent promoters, etc. $)^{1-8}$ or the design aspects (i.e. module configuration, membrane materials, surface modification, etc. $)^{3,5}$. The results of other studies indicate that the type of membrane material has a large influence on the fouling intensity ${ }^{7-17}$. Thus, the selection of appropriate membrane element for a particular application of NF process has a significant impact on the process performance.

Surface energy and charge affect the tendency of a material to stick to a surface. Repulsion forces dominate when the surface and foulant are of the same charge. In aqueous solutions, most particles posses negative charges; as a result, the negative charges on the membrane surface tend to promote repulsion forces. To prevent fouling in aqueous media, a membrane surface requires a chemistry that prefers binding to water over other materials. This implies that the membrane surface used for water treatment must be hydrophilic9,11,14,18.

One way to evaluate the relative hydrophobicity of the membrane is to measure the contact angle between the membrane surface, air and water. Varying methods such as the sessile drop, the Wilhelmy plate method, and the captive bubble method are used for contact angle measurements ${ }^{9-21}$. All these techniques allow to determine the advancing and receding angle. The difference between both angles is 'contact angle hysteresis'. The hysteresis depends on the conformation changes of the membrane and also on surface roughness. It was worthy to notice, that a wet membrane exhibits a different behavior in comparison to that of a dry membrane $e^{9-11,20,22}$.

The most widely used method is a direct measurement of the contact angle on a liquid drop deposited on a surface (sessile drop), where the contact angle is determined by constructing a tangent to the profile at the contact point of the drop with the solid surface ${ }^{12-19,22}$. This can be done on a projected image or a photograph of the drop or directly by using a telescope fitted with a goniometer eyepiece. Another similar method is the captive bubble, where a small air bubble is placed in contact with the membrane immersed in the liquid and the profile of this bubble is then measured. The most important difference between these methods is that in the captive bubble method a wet membrane is used, while in the sessile drop method the membrane should be dried before the measurement ${ }^{19}$.

Among the known methods, a dynamic measurement of the contact angle using the Wilhelmy plate method seems to be the most simple and adequate technique ${ }^{10,11,18-20,23}$. The studies of the contact angle are affected by the chemical composition, roughness, swelling, chemical heterogeneity, adsorption, desorption, energy level of 
surface electrons, and surface configuration changes ${ }^{11,19,20}$. The above factors imply that if the difference between the advancing and receding angle approaches a value of zero, the substrate is chemically and physically uniform. The details of the Wilhelmy plate method currently being studied are the influence of the penetration velocity, contact angle hysteresis influence, and adequate data acquisition $^{18-19}$.

The dynamic measurement of the contact angle is an important and useful technique in characterizing adsorption and deposition behavior of membranes in contact with protein and other organic solutions ${ }^{19}$. In particular, dynamic measurements of contact angles on membranes (immersed in protein solutions) allow to determine the affinity of protein to adsorb onto the membrane surface. These measurements are particularly useful, because they facilitate the selection of low-fouling membrane material for use in membrane bioreactors ${ }^{12}$. Intensive membrane fouling often occurs during the separation of broth, because microorganisms are present in the separated solution in addition to nutrients and organic solutes. NF process is a very effective method for separating the inorganic and organic components of the fermenting solutions. However, the permeate flux decline and the difficulty in module rinsing (fouling removal), restrict NF application ${ }^{5,9}$.

The measurement of contact angle is a relatively simple method, which can be utilized for the selection of appropriate membrane material for the separation of a given kind of broth. However, the data on contact angle measurements stated in literature indicate that the type of tensiometer and the measurement method affects the obtained results. The values of contact angle determined for the same membrane (e.g. NF90 and NF270) can differ up to $100 \% \%^{9,13,14,16}$.

The presented data (atomic force microscopy -AFM) indicated that NF90 has the roughest top layer, while NF270 has the smoothest top layer ${ }^{14}$. The used membranes comprise different polyamide chemistries. The NF270 membrane is composed of a piperazine and benzenetricarbonyl trichloride based polyamide layer on top of a polysulphone microporous support reinforced with a polyester non-woven backing layer. Benzenetricarbonyl trichloride is also a starting material for the membrane NF90, but instead of piperazine, the 1,3 phenylene diamine is used to complete the interfacial polymerization, ${ }^{9,12,14-17}$.

The NF270 membrane has a very thin semi-aromatic piperazine-based polyamide active layer, which gives it a relatively smooth surface. This is potentially the reason for the excellent performance of the membrane, specifically its high-water permeability and organic matter retention. On the other hand, the NF90 membrane consists of a fully aromatic polyamide active layer. As a result of these subtle differences in the polymer composition and morphology of the active layers, the NF90 membrane has a different contact angle than the NF270 membrane, as shown in Table 1. Large deviations of contact angle were observed which most likely result from variations in the applied procedure, $11,15-18$.

The objective of presented study was to determine the effect of sample preparation and measurement procedure on the values of dynamic contact angles. The NF90 and
Table 1. Sample preparation techniques and types of tensiometers used for contact angle measurements of membranes

\begin{tabular}{|c|c|c|c|}
\hline Membrane & $\begin{array}{l}\text { Contact } \\
\text { angle }\end{array}$ & Conditions & Lit. \\
\hline $\begin{array}{l}\text { NF270 } \\
\text { NF90 }\end{array}$ & $\begin{array}{l}40^{\circ} \\
48^{\circ}\end{array}$ & $\begin{array}{l}\text { sessile drop method, } \\
\text { goniometer (Rame Hart, } \\
\text { Mountain Lakes, NJ). }\end{array}$ & [4] \\
\hline NF270 & $30^{\circ}$ & $\begin{array}{l}\text { sessile drop method, } \\
\text { goniometer }\end{array}$ & [9] \\
\hline $\begin{array}{l}\text { SW3OHRL } \\
\text { E } \\
\text { SW3OHR }\end{array}$ & $\begin{array}{c}33^{\circ} \pm 0.4 \\
42.8^{\circ} \pm 2.3\end{array}$ & $\begin{array}{c}\text { dynamic contact angle } \\
\text { (Sigma 701, KSV } \\
\text { Instruments Ltd., Finland). } \\
\text { dry samples }\end{array}$ & [10] \\
\hline SW30HR & $24.8^{\circ} \pm 3.4$ & $\begin{array}{l}\text { sessile drop method, } \\
\text { goniometer (DM } 500 \text {, Kyowa } \\
\text { Interface Science, Japan). }\end{array}$ & [11] \\
\hline $\begin{array}{l}\text { NF270 } \\
\text { NF90 }\end{array}$ & $\begin{array}{l}39.7^{\circ} \pm 0.4 \\
67.5^{\circ} \pm 0.3\end{array}$ & $\begin{array}{c}\text { sessile drop method, } \\
\text { goniometer (DSA10, Krüss, } \\
\text { USA) } \\
\text { samples rinsed and dried for } 24 \\
\text { h before measurement }\end{array}$ & [12] \\
\hline NF270 & $64^{\circ} \pm 11$ & $\begin{array}{l}\text { sessile drop method, } \\
\text { goniometer (contact angle } \\
\text { system FTA 125), dry } \\
\text { samples }\end{array}$ & [13] \\
\hline $\begin{array}{l}\text { NF270 } \\
\text { NF90 }\end{array}$ & $\begin{array}{l}27^{\circ} \\
54^{\circ}\end{array}$ & $\begin{array}{l}\text { sessile drop method, Drop } \\
\text { Shape Analysis System DSA } \\
10 \text { Mk2 (Krüss); wet and } \\
\text { rinsed membrane }\end{array}$ & [14] \\
\hline NF30 & $88.4^{\circ} \pm 1.9$ & $\begin{array}{c}\text { sessile drop method, Drop } \\
\text { Shape Analysis System DSA } \\
10 \text { Mk2 (Krüss), wet and } \\
\text { rinsed membrane }\end{array}$ & [15] \\
\hline $\begin{array}{l}\text { NF270 } \\
\text { NF90 }\end{array}$ & $\begin{array}{l}55.0^{\circ} \\
42.5^{\circ}\end{array}$ & $\begin{array}{c}\text { NRL contact angle } \\
\text { goniometer (Rame Hart, } \\
\text { Mountain Lakes, NJ), dry } \\
\text { samples }\end{array}$ & [16] \\
\hline $\begin{array}{l}\text { NF270 } \\
\text { NF90 }\end{array}$ & $\begin{array}{l}39.7^{\circ} \pm 0.4 \\
67.5^{\circ} \pm 0.3\end{array}$ & $\begin{array}{l}\text { sessile drop method. } \\
\text { goniometer }\end{array}$ & [17] \\
\hline NF270 & $58^{\circ}$ & $\begin{array}{l}\text { sessile drop method, } \\
\text { goniometer (Rame-Hart } \\
\text { model 200-F1, USA), dry } \\
\text { membrane samples }\end{array}$ & [24] \\
\hline
\end{tabular}

NF270 membranes were used. These membranes are also investigated by several authors, which enabled the comparison of our results with those found in previous papers.

\section{EXPERIMENTAL}

\section{Membranes and materials}

Two commercially available membranes denoted NF270 and NF90 (Dow FilmTec Co., USA) were used in the presented studies. The membrane samples were obtained from the manufacturer in the form of flat sheet membranes (dimensions $1,2 \times 2 \mathrm{~m}$ - roll). The tests were carried out using several couples of samples collected from different places of the roll, therefore, the properties of the membranes have been examined adequately.

The dynamic contact angle tests were conducted using deionized water and organic solutions containing solutes with fouling propensity. These solutions were bacterial growth medium (MRS) and post-fermentation solution (Lactobacillus casei). The MRS medium (BTL Sp. z o.o, Łódź, Poland), consisted (per liter of DI water) of: 10 
$\mathrm{g}$ peptone $\mathrm{K}$ (casein hydrolysate), $8 \mathrm{~g}$ meat extract, 4 $\mathrm{g}$ yeast extract, $2 \mathrm{~g}$ dipotassium phosphate, $5 \mathrm{~g}$ sodium acetate, $2 \mathrm{~g}$ ammonium citrate, $20 \mathrm{~g}$ glucose, $0.2 \mathrm{~g}$ $\mathrm{MgSO}_{4} \cdot 7 \mathrm{H}_{2} \mathrm{O}$, and $0.05 \mathrm{~g} \mathrm{MnSO}_{4} \cdot 7 \mathrm{H}_{2} \mathrm{O}$.

MRS medium was used in precultures of Lactobacillus casei. These cells were used for lactic acid production using glycerol as a carbon source. The fermentation process was carried out continuously for five days, daily feeding into the bioreactor $10 \mathrm{~g}$ of glycerol per liter of fermenting solution. The broth was centrifuged (6000 rpm, centrifuge MPW-350R, manufactured by Med-Instruments), and filtered (membrane filter $0.45 \mu \mathrm{m}$, Millipore) after fermentation.

\section{Methods and instruments}

Hydrophilicity/hydrophobicity of the membrane was determined by dynamic contact angle measurements based on the Wilhelmy plate method. The measurements were carried out using a Sigma 701 microbalance (KSV Instrument, Ltd., Finland) interfaced with a PC for automatic control and data acquisition. The membrane sample was attached to a precise microbalance. A measurement cell containing a test liquid moved up and down at constant speed throughout each measurement for the specified number of cycles. The surface tension of test liquids was measured before beginning measurements by the Force Wilhelmy plate method at 297-298 K.

Deionized water $(0.055 \mu \mathrm{S} / \mathrm{cm})$ was used as the test liquid. The DI water was obtained by a two-stage purification of tap water using a Millipore apparatus: Elix3 (stage I) and Simplicity 185 (stage II).

New clean membranes were cut into strips measuring $15-20 \mathrm{~mm}$ in width and $25-30 \mathrm{~mm}$ in length. Measurements of dynamic contact angle were carried out using the membrane samples described in Table 2. For each type of the prepared samples, at least 10 membrane pieces collected from various place of flat sweet membrane were tested. Membrane samples (DMUB) after rinsing in DI water were naturally dried under ambient temperature (two days).

In addition, morphology of the membrane was analyzed by using a scanning electron microscope (SEM) (JSM-6100, JEOL Ltd., Tokyo, Japan).

In order to identify the functional groups on membrane surfaces, the attenuated total reflection Fourier transform infrared (ATR-FTIR) analyses was performed using a Nicolet 380 FT-IR spectrophotometer connected with Smart Orbit diamond ATR accessory (Thermo Electron Corp., USA). Over ten ATR-FTIR spectra were obtained for every membrane type, with each spectrum averaged from 50 scans collected from 600 to $4000 \mathrm{~cm}^{-1}$ wave numbers at $0.482 \mathrm{~cm}^{-1}$ resolutions.

A cross-flow NF membrane flat module (SEPA cell set-up) manufactured by GE/Osmonics was used in this study. The surface area of the membrane was 106.2 $\mathrm{cm}^{2}(8.4 \mathrm{~cm} \times 10.5 \mathrm{~cm})$, and the cross-sectional area of the membrane module was $1.1 \mathrm{~cm}^{2}(8.4 \mathrm{~cm} \mathrm{x} 0.2 \mathrm{~cm})$. Prior to each experiment, the membrane was stabilized at $\Delta \mathrm{P}=2$ bar using $\mathrm{DI}$ water, and the flow velocity was adjusted to $30.4 \mathrm{~cm} / \mathrm{s}$. After stabilizing the membrane, the rejection experiments were conducted with salt solution $\left(2 \mathrm{~g} \mathrm{MgSO}_{4} / \mathrm{dm}^{3}\right)$. The membrane permeability was then determined. Unless otherwise stated, the permeate and
Table 2. The kind of samples (NF90 and NF270 membranes) used for study of contact angle

\begin{tabular}{|l|l|}
\hline $\begin{array}{l}\text { Kind of } \\
\text { samples }\end{array}$ & \multicolumn{1}{c|}{ Description } \\
\hline DM & dry membrane strips, without any pre-treatment \\
\hline DMUB & $\begin{array}{l}\text { dry membrane strips, previously cleaned with DI } \\
\text { water in an ultrasound bath }\end{array}$ \\
\hline DMGSL & $\begin{array}{l}\text { dry samples; two dry strips of membrane were glued } \\
\text { (supporting layer to supporting layer) using adhesive } \\
\text { tape }\end{array}$ \\
\hline DMGTL & $\begin{array}{l}\text { dry samples, two dry strips of membrane were glued } \\
\text { (top layer to top layer) using adhesive tape }\end{array}$ \\
\hline WM & $\begin{array}{l}\text { wet membrane strips; the membrane strips were } \\
\text { immersed in DI water and were stored a few days } \\
\text { with water replaced daily }\end{array}$ \\
\hline WMGSL & $\begin{array}{l}\text { wet samples; two dry strips of membrane were glued } \\
\text { (supporting layer to supporting layer) using ad hesive } \\
\text { tape and immersed in DI water for two days } \\
\text { (replaced daily) }\end{array}$ \\
\hline WMGTL & $\begin{array}{l}\text { wet samples; two dry strips of membrane were glued } \\
\text { (top layer to top layer) using adhesive tape and } \\
\text { immersed in DI water over two days }\end{array}$ \\
\hline
\end{tabular}

retentate were recirculated back to the feed reservoir. Feed and permeate samples were taken for analysis at specified time.

\section{RESULTS}

\section{Membrane characterisation}

The formation of deposits on the membrane surface depends, in large part, on the chemical composition of the membrane and its roughness. The performed SEM observations confirmed that the NF90 exhibits a larger roughness than NF270 (Fig. 1). The observed roughness is several times larger than those occurring on the surface of the NF270 membrane. Both membranes are composed of three layers, the thinner two uppermost layers are supported by a polyester non-woven backing layer (Fig.2). SEM observations revealed that both NF270 and NF90 membranes have a similar morphology of the polysulphone microporous support and polyester supporting layer.

In order to verify the functional groups on the membrane surfaces, ATR-FTIR spectra of the investigated membranes were obtained. The results presented in Figs. 3 and 4 confirmed a difference in the chemical composition of the top layer and support layer of the NF90 membrane. Similar differences were observed in the spectra obtained for the NF270 membrane. Moreover, the IR spectra of the support layer for NF90 and NF270 membranes presented a similar shape of the peaks, which confirmed that the same polyester material was used for manufacture of these membranes (Fig. 3).

In the Fig. 4 was compared the IR spectra of the top layer of the NF90 and NF270 membranes. Although differences in the chemical composition of the top layers of these NF membranes are confirmed by several authors $\mathbf{9}^{\mathbf{9}, 12-14}$, both IR spectra look similar and there are not large differences in the obtained results. Significant differences, which can be attributed to the top layer, were observed for absorption at 1668, 1608, and 1550 $\mathrm{cm}^{-1}$ (Fig. 4). The carbonyl groups of amides absorb at particularly low IR frequencies, about 1640 to $1680 \mathrm{~cm}^{-1}$, whereas amides I and II absorb around 1540 and 1680 $\mathrm{cm}^{-125}$. Moreover, the presented IR spectra are almost 
A)

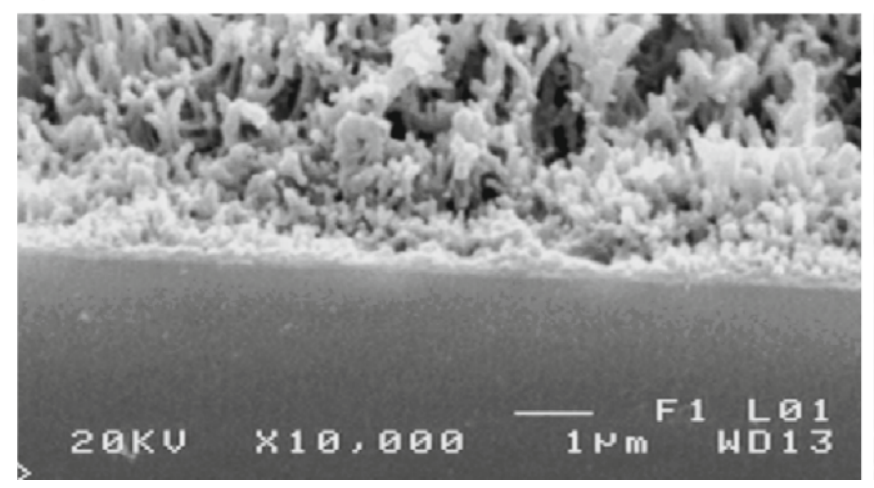

B)

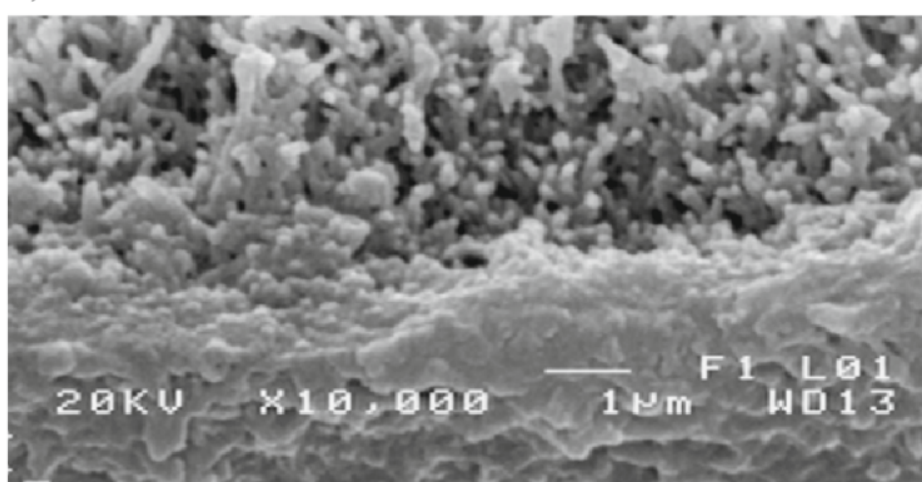

Figure 1. SEM images of cross-section of NF270 (A) and NF90 (B) membranes. The membrane top layer (bottom part of the pictures) supported by the microporous polysulphone layer (upper part of the pictures)

A)

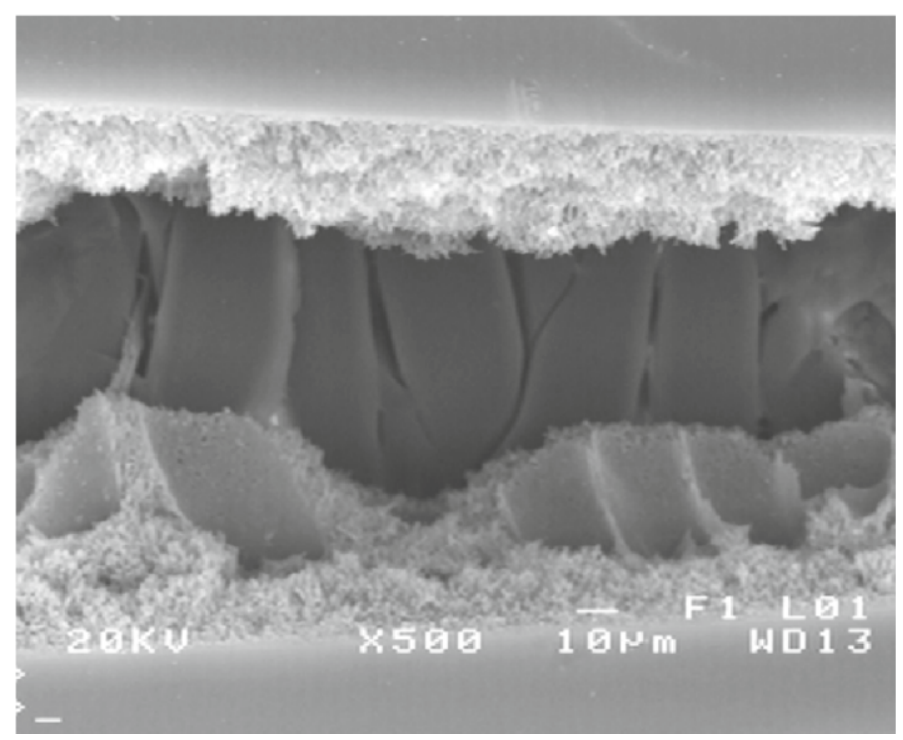

B)

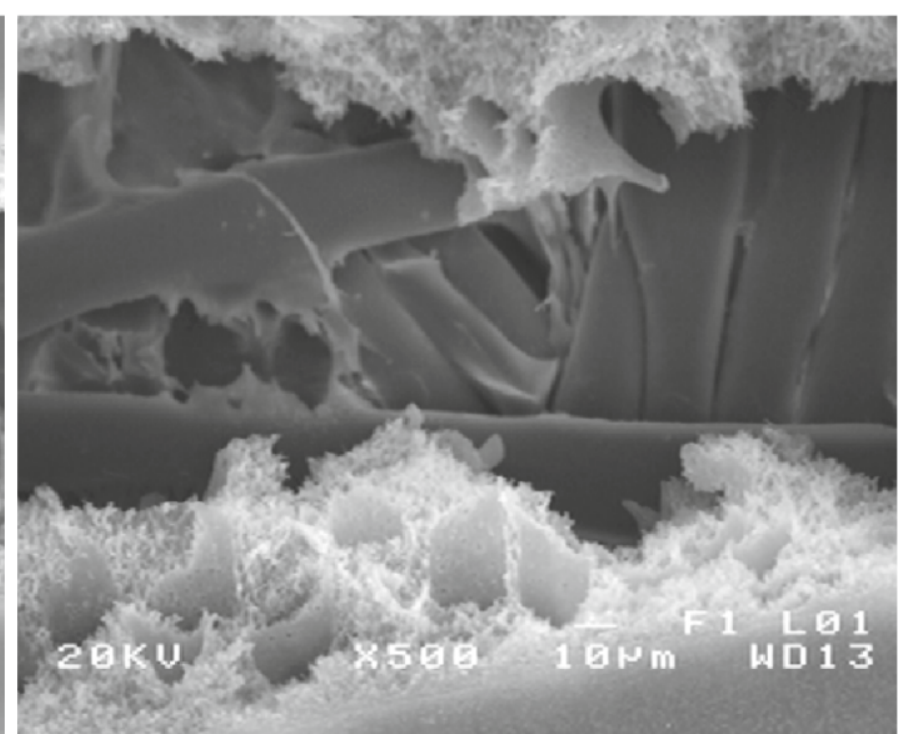

Figure 2. SEM images of three layers the composite NF270 (A) and NF90 (B) membranes (top layers were broken in liquid nitrogen). In the middle - the polyester non-woven supporting layer

identical in the shape and peak intensity compared to the IR spectra obtained for pure polysulphone (Sigma Aldrich). This results from the fact that the presented membranes IR spectra were generated not only for the chemical structure of top layer, but also for the porous polysulphone layer. The polyamide top-layer is very thin, and the polysulphone middle support layer can also be analyzed because of the greater penetration depth of

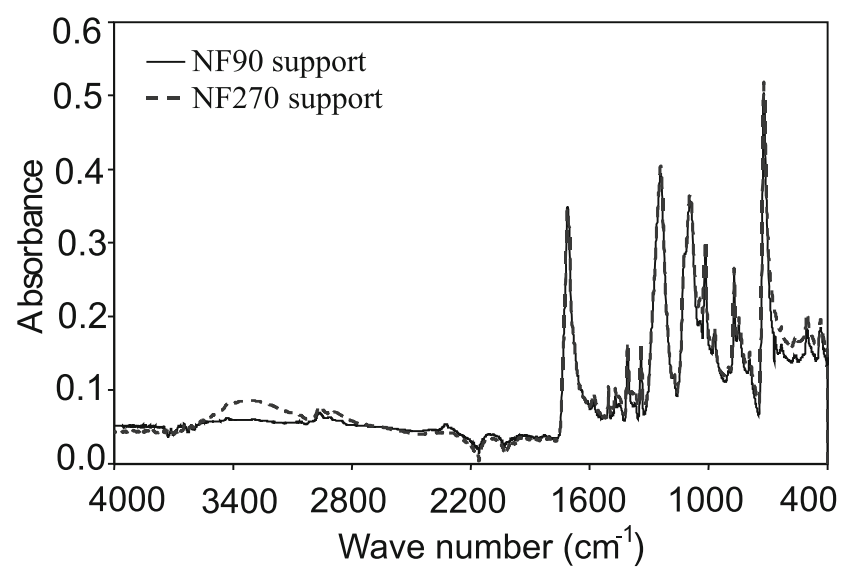

Figure 3. ATR- FTIR spectra comparison of the supporting layers obtained for the virgin NF90 and NF270 membranes
ATR measurements. Moreover, the samples of membranes used were split into their component layers, and the obtained IR spectra of only the polysulphone layer were similar to that presented in Fig. 4.

Several peaks observed in the IR spectra were characteristic for the studied membrane material, especially in the wave number ranging between 500 and $1800 \mathrm{~cm}^{-1}$ (Figs. 4 and 5). The broad band between 2800 and 3000

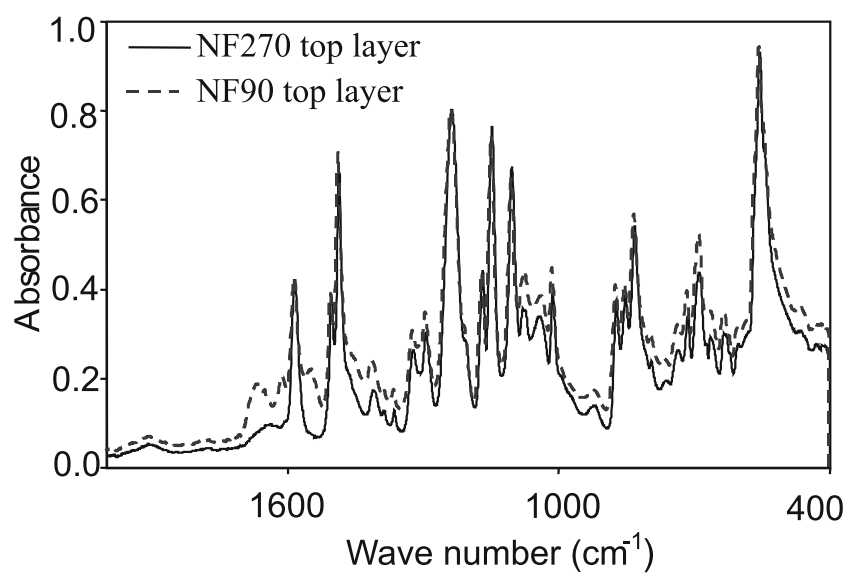

Figure 4. Comparison of ATR- FTIR spectra presented the composition of the top layers obtained for the virgin NF270 and NF90 membranes 
Pol. J. Chem. Tech., Vol. 14, No. 3, 2012

$\mathrm{cm}^{-1}$ results from $\mathrm{C}-\mathrm{H}$ stretching vibrations. The absorption at 1364 and $1387 \mathrm{~cm}^{-1}$, and the band at $1486 \mathrm{~cm}^{-1}$ result from scissoring and stretching vibration of the $\mathrm{CH}_{3}$, respectively. The peaks around 1584, and 1503 and 1408 $\mathrm{cm}^{-1}$ can be assigned to aromatic $\mathrm{C}=\mathrm{C}$ stretching. The stretching vibration of aromatic $\mathrm{C}-\mathrm{C}$ resulted in peaks at 1013 and $1080 \mathrm{~cm}^{-1}$. The absorption at 1321, 1294, 1168 and 1147 results from the stretching vibration of $\mathrm{SO}_{2}$ groups. The results of $\mathrm{Ar}-\mathrm{O}-\mathrm{Ar}$ stretching vibrations occur at frequencies around $1236 \mathrm{~cm}^{-1}$. The peaks at $831 \mathrm{~cm}^{-1}$ are connected with deformation vibrations of aromatic rings with 1,4 substitution. The rest of the peaks in the range of 600 to $900 \mathrm{~cm}^{-1}$ also result from the presence of aromatic rings.

The majority of the peaks obtained in the IR spectra result from the polysulphone layer; however, there are other functional groups that also absorb in this region ${ }^{25}$. Since most organic compounds contain at least some saturated $\mathrm{C}-\mathrm{H}$ bonds and some $\mathrm{CH}_{3}$ and $\mathrm{CH}_{2}$ groups, all these bands are common in the IR spectra. On the other hand, the peaks around $3300-3400 \mathrm{~cm}^{-1}$, besides $(-\mathrm{COH})$ groups, may be attributed to a stretching vibration of $\mathrm{N}-\mathrm{H}$ and carboxyl groups $(-\mathrm{COOH})$ groups of the polyamide layer ${ }^{10}$. Therefore, the observed peaks of the spectra may also be attributed to other components of the top layer.

During production, preservation compounds that allow for long-term storage often impregnate the membranes. These compounds are then removed before module utilization by rinsing with clean water. Comparison of the IR spectra of virgin and rinsed membranes indicated that after membrane rinsing, the peaks at 1043 and 900 $\mathrm{cm}^{-1}$ disappeared, and the intensity of the broad band between 3000 and $3800 \mathrm{~cm}^{-1}$ was decreased (Fig. 5). These results confirmed that the used membranes were impregnated with preservation compounds. Alcohol O-H bonds absorb over a wide range of frequencies is centered around $3300 \mathrm{~cm}^{-1}$ and strong C-O stretching absorption is centered near $1060 \mathrm{~cm}^{-1}$. These results suggest that the membrane might contain glycerol.

\section{Study of dynamic contact angle}

The results of the dynamic contact angle studies indicate that the values obtained depend on a large scale on the method of membrane sample preparation and

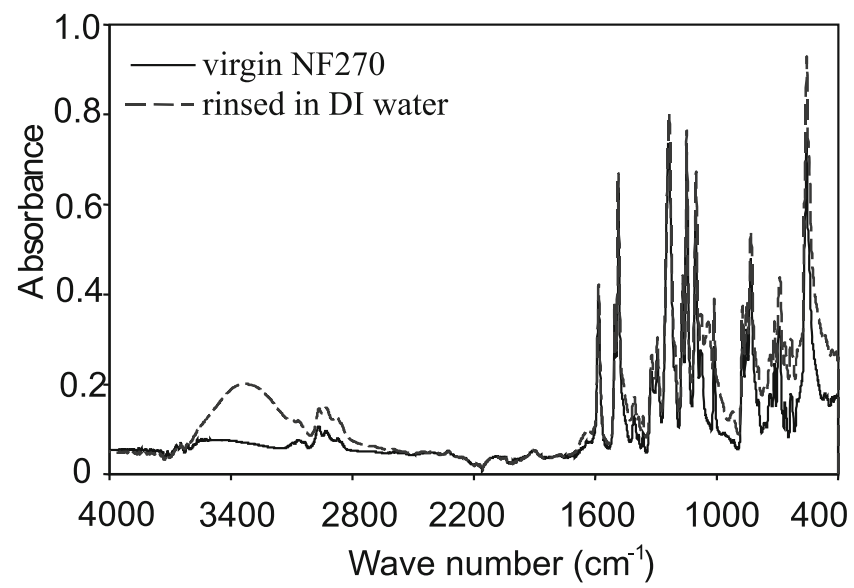

Figure 5. Comparison of ATR- FTIR spectra the top layers obtained for the NF270 membrane virgin and rinsed in DI water

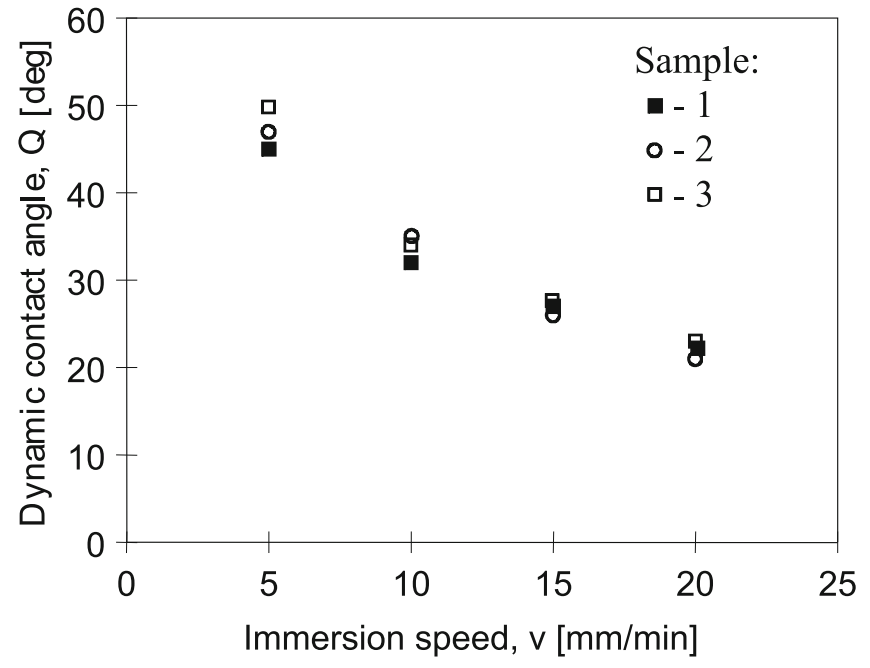

Figure 6. Influence of immersion speed on the results of dynamic contact angle (advancing) obtained using the Wilhelmy plate method. Membrane NF270, glued and rinsed (WMGSL)

the parameters designated for each test. These observations explain the variations presented in results of other authors (Table 1).

One of the parameters of the tensiometer operation is the speed of immersion and emersion of the membrane sample. The results in Fig. 6 show that for speeds between $5-20 \mathrm{~mm} / \mathrm{min}$, the values of the contact angle $(\Theta)$ may vary up to $100 \%$ for the same sample. Tests conducted for different materials (glass, PTFE, polyethylene, polypropylene) stated that for a speed of $10 \mathrm{~mm} / \mathrm{min}$ of immersion and emersion the obtained values of angle $\Theta$ were closest to the literature values for the given material, which in the case of NF270 and NF90 range from $27-39^{\circ}$ and $42-69^{\circ}$ (Table 1 ). The tested sample was immersed to a depth of $10 \mathrm{~mm}$. During the first 3 $\mathrm{mm}$ of immersion/emersion of the sample, the balance reading was nonlinear and as a result, the "ignore first $3 \mathrm{~mm}$ " function/parameter was applied to reduce the inaccuracy caused by the phenomenon.

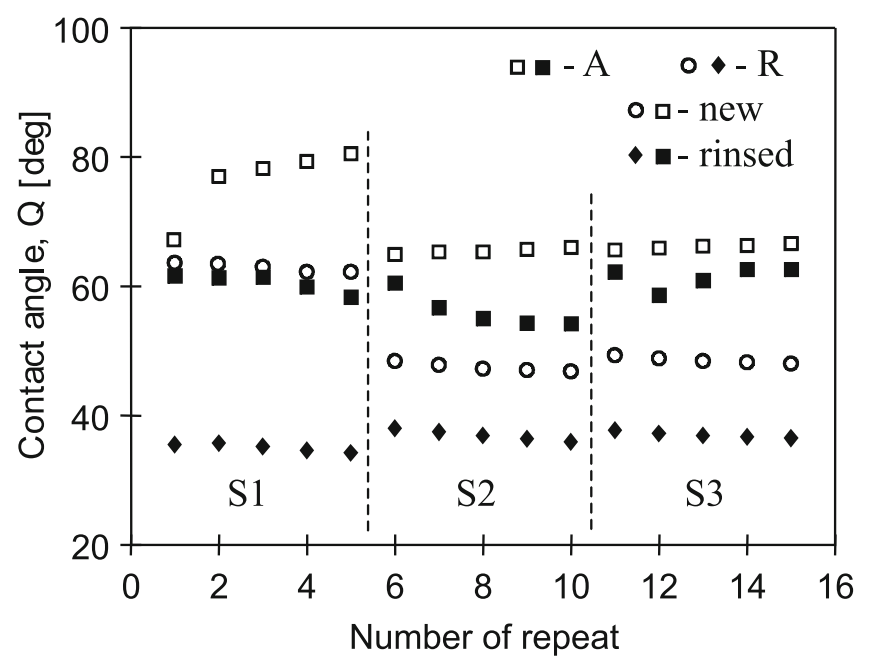

Figure 7. The values of advancing (A) and receding (R) contact angle obtained for dry samples of NF270 membrane. New - virgin samples (DM); rinsed membrane samples previously cleaned with DI water in an ultrasound bath (DMUB). S1-S3 consecutive measurement series 
Contact angle measurements indicate that the presence of preservation compounds has a significant influence on the results (Fig. 7). Thus, membrane rinsing is necessary for accurate $\Theta$ value. Both tensiometer measurements and ATR-FTIR study indicated that rinsing for several minutes in an ultrasonic bath or 2-3 days of soaking (DI water) removed the extraneous compounds from the membrane.

Depending on the measurement technique used, the value of the contact angle may be determined for dry or wetted membranes. The conducted study of dynamic contact angles indicated that the results for dry membrane samples varied significantly compared to the wet samples (Fig. 8). Membranes in membrane modules are wet, thus it is necessary to define the properties of the wetted membrane. Furthermore, applying the relatively short ultrasonic bath (instead DI water soaking) did not adequately wet the membranes. Tests carried out for samples prepared by these two methods were characterized by large variations. Stable results were obtained when samples were soaked in DI water for at least 24 hours prior to testing. Most likely, the degree of sample hydration affects the variations in contact angle measurements for the NF90 and NF270 membranes obtained by

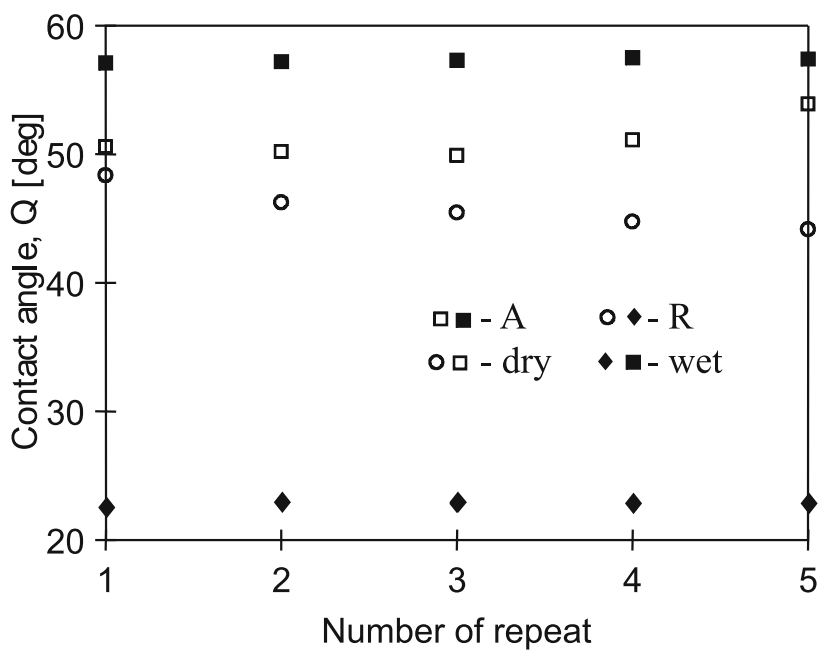

Figure 8. The values of dynamic contact angle (A - advancing and $\mathrm{R}$ - receding) obtained for dry (DMUB) and wet (WM) samples of NF270 membrane

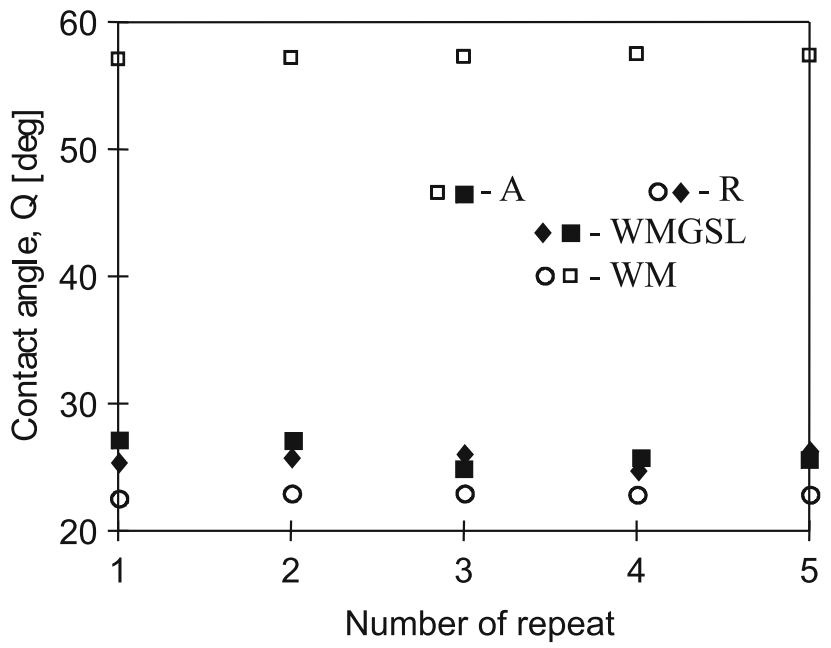

Figure 9. The dynamic contact angle obtained for glued (WMGSL) and non-glued (WM) samples of NF270 membrane other authors (Table 1), e.g. NF90 is generally accepted to have a contact angle larger than NF270, but reversed measurements may be acquired for dry samples ${ }^{\mathbf{1 3}, \mathbf{1 6}}$.

The requirement for sample hydration can be fulfilled using dynamic contact angle measurements. However, the top and support layers of the NF90 and NF270 membranes differ and thus have different contact angle values. Therefore, immersion of the samples gave the average value of the two separate surfaces, but not solely top layer. This was correlated by the conducted tests in which two samples of membrane were taped, so that only one surface of the membrane was measured (either the top or supporting layer). The significant differences in the value of contact angle between WMGSL and WM samples were observed (Fig. 9). These indicate that the use of un-taped membrane samples (WM) does not give accurate values of angle $\Theta$ for the top layer, which is the layer of interest since fouling of this side of the membrane influences flux decline.

\section{Determination of fouling intensity}

Adsorption of feed components to the membrane surface (organic fouling) is one of the main processes decreasing flux during NF process ${ }^{\mathbf{4}, 11}$. Organic fouling changes the chemical composition of the membrane surface, which affects the contact angle. Therefore, identifying gradual changes in contact angles can determine organic fouling progression.

Taped membranes samples (support layer to support layer), wetted for 2 days in DI water prior to testing (WMGSL), were used to study organic fouling. First, the contact angle was measured using DI water; the values were similar to those obtained previously (e.g. 27-30 and $53-57^{\circ}$ for NF270 and NF90, respectively). DI was then replaced by centrifuged broth from the bioreactor (glycerol fermented by L.casei) and several immersion-emersion cycles were conducted with the tensiometer. The depth of sample immersion was $10 \mathrm{~mm}$ and the rate was $10 \mathrm{~mm} / \mathrm{min}$. Thus, every cycle lasted approximately 2 minutes.

The results obtained from the NF270 membrane show that angle $\Theta$ quickly increased to $46.8^{\circ}$ during the first

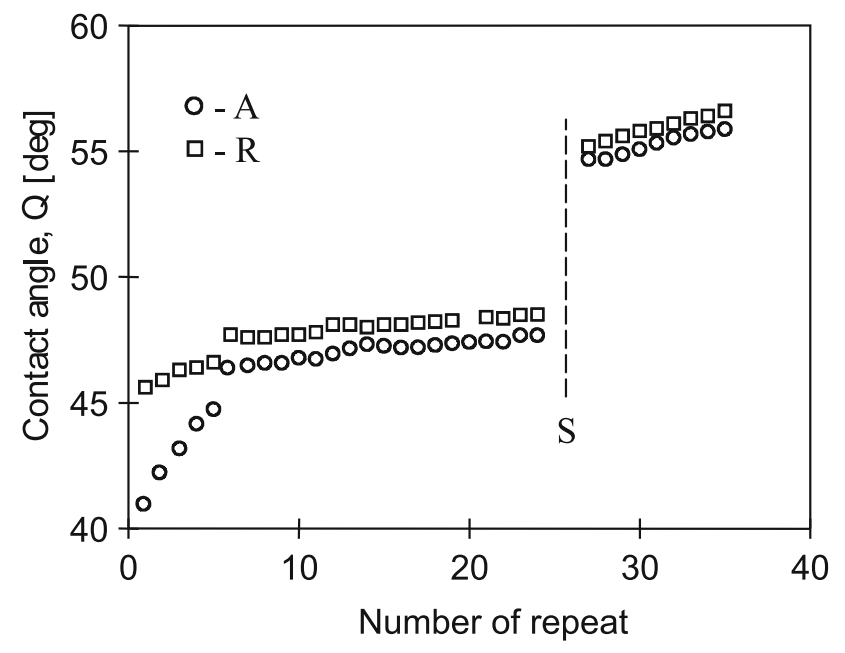

Figure 10. Changes the values of contact angle (A - advancing and R - receding) during NF270 membrane samples (WMGTL) immersed in the broth (glycerol fermented by $L$. casei). Point $\mathrm{S}-$ membrane soaked for $3 \mathrm{~h}$ in the broth 


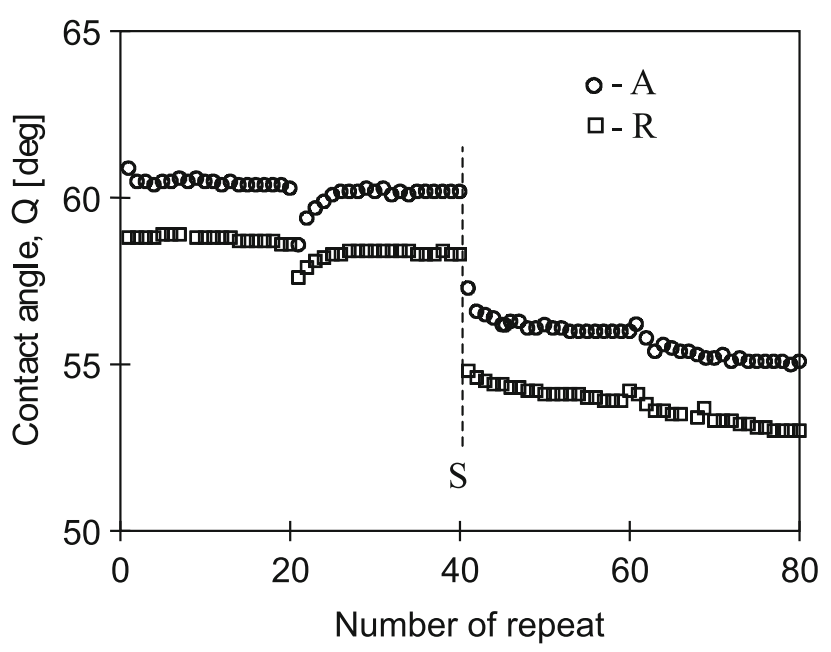

Figure 11. Changes the values of contact angle (A - advancing and $\mathrm{R}$ - receding) during NF90 membrane samples (WMGTL) immersed in the broth (glycerol fermented by $L$. casei). Point $\mathrm{S}-$ membrane soaked for 2 $\mathrm{h}$ in the broth

20 min of measurements (Fig. 10). Next, the value rose more slowly, reaching $47.7^{\circ}$ after $50 \mathrm{~min}$. In order to increase the fouling intensity, the sample membrane was immersed for 3 hours in the test broth, after which time contact angle readings were continued. This prolonged immersion caused angle $\Theta$ to grow from 47.7 to $54.7^{\circ}$. During the subsequent 9 immersion/emersion cycles, the value increased to $55.9^{\circ}$. Thus, contact angle changed by $15.9^{\circ}$ over $260 \mathrm{~min}$.

The changes of contact angle measurements for NF90 were conducted similarly. However, the trend in angle $\Theta$ values was opposite, because the angles decreased with time (Fig. 11). After the initial 80 minutes of study the membrane emersion was stopped, and the sample was continuously immersed in the broth for 2 hours. This caused a decrease in the contact angle from 60 to $57.3^{\circ}$; a change two times less than for the 3 hour immersion of NF270. After 30 subsequent cycles, the contact angle of NF90 stabilized at $55.1^{\circ}$ and did not change during the next 10 cycles. In total, the contact angle changed $5.8^{\circ}$ during 280 minutes, or 3 three times less than the angle for NF270.

In the previously released literature, the NF90 membrane was usually determined to be more susceptible to fouling than NF270 due to its roughness ${ }^{\mathbf{1 2}}$. However, in our case the obtained experimental results indicate that the membrane NF90 exhibits the larger resistance to fouling. Probably the applied feed pre-treatment (centrifugation and microfiltration) removed the colloidal substances (colloidal fouling), therefore; organic fouling become dominates. As a consequence of adsorption of organic compound on the membrane surfaces, the contact angle obtained for both fouled membranes was about $55-56^{\circ}$ and this value was closer to the contact angle of clean NF90 membrane. NF270 had greater organic fouling because the contact angle of virgin membrane was significantly smaller $\left(27^{\circ}\right)$.

The results of the contact angle measurements suggest that NF90 should be more resistant to fouling during the separation of broth from lactic acid production. Low pressure NF was performed to test this hypothesis. To limit the fouling intensity, the permeate flux was redu- ced using transmembrane pressure equal to $0.18 \mathrm{MPa}$. Before the study, the membrane samples were immersed in DI water (changed daily) for 3 days. During the first $5 \mathrm{~h}$ of NF, DI water was used as the feed, and a flux of $19.3 \mathrm{dm}^{3} / \mathrm{m}^{2} \mathrm{~h}$ was obtained. After using $\mathrm{MgSO}_{4}$ solution (2000 ppm), the flux decreased to $13.5 \mathrm{dm}^{3} / \mathrm{m}^{2} \mathrm{~h}$ and the rejection was $98.8 \%$. For the next $20 \mathrm{~h}$, the separation of broth was carried out. Finally, the module was rinsed using DI water, and the maximum permeate flux was measured to be $15.1 \mathrm{dm}^{3} / \mathrm{m}^{2} \mathrm{~h}$.

A similar NF procedure was completed for the NF270 membrane. For the $\mathrm{MgSO}_{4}$ solution, the permeate flux and the rejection was $17.2 \mathrm{dm}^{3} / \mathrm{m}^{2} \mathrm{~h}$ and $90.5 \%$, respectively. Due to the fouling phenomenon, the maximum permeate flux decreased from 28 to $14 \mathrm{dm}^{3} / \mathrm{m}^{2} \mathrm{~h}$, and after $3 \mathrm{~h} \mathrm{NF}$ (DI water as a feed), increased to $18.3 \mathrm{dm}^{3} /$ $\mathrm{m}^{2} \mathrm{~h}$. The value shows that the water removed part of the fouling layer. A comparison of the obtained results for both membranes was presented in Table 3. Due to fouling, the hydraulic permeability of the used NF90 and NF270 membranes decreased by $21.7 \%$ and $34.6 \%$, respectively.

The FTIR-ATR study was performed for samples of membranes taken from NF module. Fig. 12 presents the IR spectra obtained for the clean and fouled NF270 membrane. Significant changes in intensity and peak height were observed for only NF270, which confirms that this membrane underwent greater fouling than NF90.

Table 3. Changes of hydraulic permeability of NF90 and NF270 membranes

\begin{tabular}{|l|c|c|}
\hline \multirow{2}{*}{ Feed and membrane state } & \multicolumn{2}{|c|}{$\begin{array}{c}\text { Hydraulic permeability }\left[\mathrm{dm}^{3} / \mathrm{m}^{2} \mathrm{~h}\right. \\
\mathrm{MPa}]\end{array}$} \\
\cline { 2 - 3 } & $\mathrm{NF90}$ & $\mathrm{NF} 270$ \\
\hline $\begin{array}{l}\text { DI water and new } \\
\text { membranes }\end{array}$ & 107.2 & 155.5 \\
\hline 2000 ppm $\mathrm{MgSO}_{4}$ & 75.0 & 95.6 \\
\hline Post-fermenting solution & 71.3 & 77.8 \\
\hline $\begin{array}{l}\text { DI water and fouled } \\
\text { membranes }\end{array}$ & 83.9 & 101.7 \\
\hline
\end{tabular}

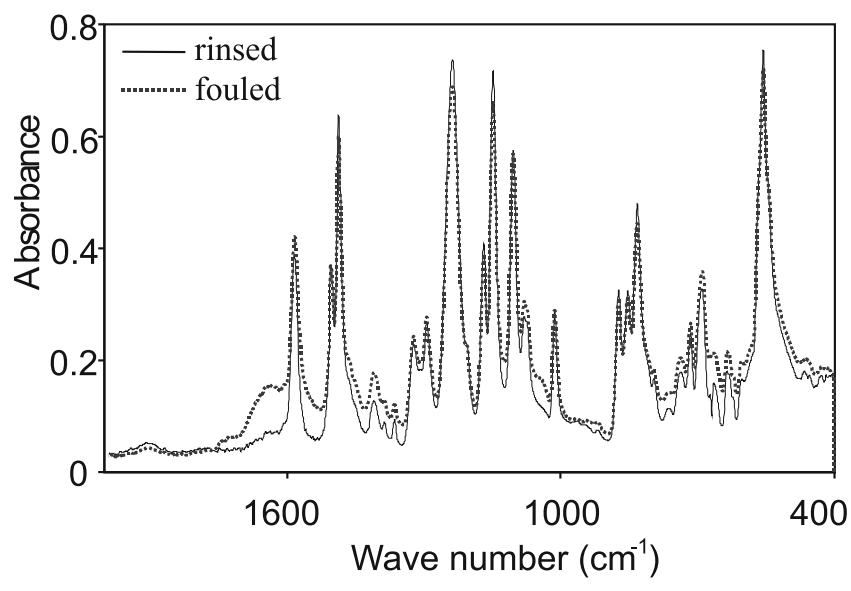

Figure 12. Comparison of ATR- FTIR spectra the top layers obtained for the NF270 rinsed in water and fouled membrane samples

\section{CONCLUSIONS}

Dynamic contact angle measurement (Willhelmy plate method) is an effective method for the characterisation of membrane materials. However, sample preparation is very important for correct analysis. The degree of 
membrane hydration has a major influence on the results of contact angle measurements. Therefore, membrane samples should be immersed a minimum of one day in deionized water before the study. Moreover, two pieces of membrane sample should be glued together (support layer to support layer) in order to generate the contact angle of only the top layer.

The FTIR-ATR and the dynamic contact angle tests underscored the fact that the membrane material has a large affect on the fouling intensity. Adsorption of compounds in the feed to the membrane surface changes its contact angle. The studies confirmed the relationship between fouling intensity and the degree of the contact angle. This angle changes until it reaches an equilibrium value. The greater the difference between this value and the value of clean un-fouled membrane, the greater the fouling expected for the membrane. Of the two membranes tested, NF90 should be more resistant to fouling.

The NF270 and NF90 membranes were used to separate broth from glycerol fermentation (Lactobacillus casei). The NF studies confirmed that NF270 membrane underwent greater fouling than NF90.

\section{Acknowledgements}

The study was conducted within the framework of the project: Biotechnological conversion of glycerol to polyols and dicarboxylic acids; (No 01.01.02-00-074/09) co-funded by The European Union from The European Regional Development Funds within the framework of the Innovative Economy Operational Programme 2007-2013.

\section{LITERATURE}

1. Drioli, E., Curcio, E., Criscuoli, A. \& Di Profio, G. (2004). Integrated system for recovery of $\mathrm{CaCO}_{3}, \mathrm{NaCl}, \mathrm{MgSO}_{4} 7 \mathrm{H}_{2} \mathrm{O}$ from nanofiltration retentate. J. Membr. Sci., 239, 7-38. DOI:10.1016/j.memsci.2003.09.028.

2. Karakulski, K. \& Gryta, M. (2005). Water demineralisation by NF/MD integrated processes. Desalination, 177, 109-119. 10.1016/j.desal.2004.11.018.

3. Singh, R. Hybrid membrane systems for water purification, Elsevier, Oxford 2006.

4. Bellona, Ch., Marts, M. \& Drewesa, J.E. (2010). The effect of organic membrane fouling on the properties and rejection characteristics of nanofiltration. Sep. Purif. Technol., 74. 44-54. doi:10.1016/j.seppur.2010.05.006.

5. Schäfer, A.I., Fane, A.G. \& Wait, T.D. (eds.) (2005). Nanofiltration: Principles and Application. Elsevier, Oxford.

6. Gryta, M. (2008). Fouling in direct contact membrane distillation, J. Membr. Sci., 325, 383-394. doi:10.1016/j.memsci.2008.08.001.

7. Xu, P., Drewes, J.E., Kim, T.U., Bellon, Ch. \& Amy, G. (2006). Effect of membrane fouling on transport of organic contaminants in NF/RO membrane applications. J. Membr. Sci., 279. 165-175. doi:10.1016/j.memsci.2005.12.001.

8. Gryta, M. (2008). Chemical pretreatment of feed water for membrane distillation. Chem. Pap., 62, 100-105. DOI: 10.2478/s11696-007-0085-5.

9. Mänttäri, M., Pekuri, T. \& Nyström, M. (2004). NF270, a new membrane having promising characteristics and being suitable for treatment of dilute effluents from the paper industry. J. Membr. Sci., 242, 107-116. doi:10.1016/j.memsci.2003.08.032.

10. Lee, W., Hoon Ahn, Ch., Hong, S., Kim, S., Lee, S., Baek, Y. \& Yoon, J. (2010). Evaluation of surface properties of reverse osmosis membranes on the initial biofouling stages under no filtration condition. J. Membr. Sci., 351, 112-122. DOI:10.1016/j.memsci.2010.01.035.
11. Lee, S., Lee, E., Elimelech, M. \& Hong, S. (2011). Membrane characterization by dynamic hysteresis: Measurements, mechanisms, and implications for membrane fouling. J. Membr. Sci., 366, 17-24. doi:10.1016/j.memsci.2010.09.024.

12. Subramani, A., Huang, X., \& Hoek, E.M.V. (2009). Direct observation of bacterial deposition onto clean and organicfouled polyamide membranes. J. Colloid and Inter. Sci., 336, 13-20. doi:10.1016/j.jcis.2009.03.063.

13. Chang, E.-E., Chen, Y.-W., Lin, Y.-L., \& Chiang, P.-Ch. (2009), Reduction of natural organic matter by nanofiltration process, Chemosphere, 76, 1265-1272. doi:10.1016/j.chemosphere.2009.04.053.

14. Boussu, K., Zhang, Y., Cocquyt, J., Van der Meeren, P., Volodin, A., Van Haesendonck, C., Martens, J.A. \& Van der Bruggen, B., (2006). Characterization of polymeric nanofiltration membranes for systematic analysis of membrane performance. J. Membr. Sci., 278, 418-427. doi:10.1016/j. memsci.2005.11.027.

15. Boussu, K., Van der Bruggen, B., Volodin, A., Snauwaert, J., Van Haesendonck, C. \& Vandecasteele, C. (2005). Roughness and hydrophobicity studies of nanofiltration membranes using different modes of AFM. J. Colloid Interf. Sci., 286, 632-638. doi:10.1016/j.jcis.2005.01.095.

16. Nghiem, L.D., Schafer, A.I. \& Elimelech, M. (2005). Nanofiltration of hormone mimicking trace organic contaminants. Sep. Sci. Technol., 40, 2633-2649. DOI:10.1080/01496390500283340.

17. Subramania, A. \& Hoekb, E.M.V. (2008). Direct observation of initial microbial deposition onto reverse osmosis and nanofiltration membranes. J. Membr. Sci., 319, 111-125. doi:10.1016/j.memsci.2008.03.025.

18. Palacio, L., Calvo, J.I., Pradanos, P., Hernandez, A., Vaisanen, P. \& Nystrom, M. (1999). Contact angles and external protein adsorption onto UF membranes. J. Membr. Sci. 152, 189-201. doi:10.1016/SO376-7388(98)00203-8.

19. Rosa, M.J. \& de Pinho, M.N. (1997). Membranes surface characterization by contact angle measurements using the immersed method. J. Membr. Sci., 131, 167-180. doi:101016/ SO376-7388(97)00043-4.

20. Lee, E., Lee, S. \& Hong, S. (2010). A new approach to the characterization of reverse osmosis membrane by dynamic hysteresis. Desalin. Water Treat., 18, 257-263. doi:10.5004/ dwt.2010.1782.

21. Huang, F.L., Wang, Q.Q., Wei, Q.F., Gao, W.D., Shou, H.Y. \& Jiang, S.D. (2010). Dynamic wettability and contact angles of poly(vinylidene fluoride) nanofiber membranes grafted with acrylic acid, eXPRESS Polymer Letters. 4 (9), 551-558. DOI:10.3144/expresspolymlett.2010.69.

22. Zawodzinski, T.A., Gottesfeld, S., Shoichet, S. \& McCarthy, T.J. (1993). The contact angle between water and the surface of perfluorosulphonic acid membranes, J. Applied. Electrochem., 23, 86-88. DOI: 10.1007/BF00241582.

23. Wang, K.Y., Foo, S.W. \& Chung, T.S. (2009). Mixed matrix PVDF hollow fiber membranes with nanoscale pores for desalination through direct contact membrane distillation. Ind. Eng. Chem. Res., 48, 4474-4483. DOI: 10.1021/ie8009704.

24. Hajibabania, S., Verliefde, A., McDonald, J.A., Khan, S.J. \& Le-Clech, P. (2011). Fate of trace organic compounds during treatment by nanofiltration. J. Membr. Sci., 373, 130-139. doi:10.1016/j.memsci.2011.02.040.

25. Wade, L.G. (2010). Organic chemistry, 7 th. ed., Pearson Prentice Hall, NY USA. 